\title{
Partisipasi dan Pemberdayaan Sumber Daya Lokal Sebagai Upaya Pengurangan Risiko Bencana Berbasis Komunitas di Pidie Jaya Aceh Guna Mendukung Keamanan Nasional
}

\author{
Riskina Tri Januarti*, Anisa Nurur Rachmatika, Tri Winugroho, Syamsul Maarif, \\ Adi Subiyanto \\ Program Studi Manajemen Bencana, Universitas Pertahanan, Bogor \\ *Email: riskina.tri@gmail.com \\ DOI: https://doi.org/10.33369/pendipa.5.3.394-402
}

\begin{abstract}
[Participation and Empowerment of Local Resources as Community-Based Disaster Risk Reduction Efforts in Pidie Jaya Aceh to Support National Security]. Pidie Jaya District, Aceh Province has geographical conditions that include coastal and mountainous areas as well as the Great Sumatran Fault that stretches from Lampung to the Andaman Sea. This situation makes Pidie Jaya an area prone to disaster risk. Disaster Risk Reduction (DRR) can be a strategy in an effort to reduce vulnerability and increase capacity in disaster-prone areas. This study aimed to analyze community-based DRR efforts (CBDRM) which include participation and empowerment of local resources in the community in creating independence in Pidie Jaya District. The subjects in this study were the people of Pidie Jaya Regency. The method used in this research was descriptive qualitative using data sourced from interview data and documentation. Research results from the triangulation process show that the participation and empowerment of the people of Pidie Jaya Regency in Community-Based Disaster Risk Reduction efforts is still not running optimally, but it has increased understanding of disaster science in the area including knowledge, culture, anticipation, and mitigation. The principle of Building Back Better is implemented by the Government of Pidie Jaya, namely by reconstructing the lives of community groups through reducing vulnerability and increasing the ability to avoid risk factors for future disasters. Approaches through religious and dayah leaders take part in providing outreach and education. The result of CBDRM Pidie Jaya is the establishment of two Disaster Resilient Villages / Gampong located in the coastal area, namely Desa Lancang Kec. Bandar Baru and Desa Meuraksa district of Meureudu.
\end{abstract}

Keywords: Disaster Risk, Community Based Disaster Risk Reduction (CBDRM), community capacity, Pidie Jaya district.

\begin{abstract}
ABSTRAK
Kabupaten Pidie Jaya, Provinsi Aceh memiliki kondisi geografis yang mencakup kawasan pesisir dan pegunungan serta adanya Great Sumatran Fault yang membentang dari Lampung sampai laut Andaman. Keadaan ini menimbulkan Pidie Jaya sebagai wilayah yang rawan terhadap risiko bencana. Pengurangan risiko bencana (PRB) dapat menjadi strategi dalam upaya menekan kerentanan dan meningkatkan kapasitas di wilayah rawan bencana. Penelitian ini bertujuan untuk menganalisis upaya PRB berbasis komunitas (PRBBK) yang didalamnya meliputi partisipasi dan pemberdayaan sumber daya lokal di masyarakat dalam menciptakan kemandirian di Kabupaten Pidie Jaya. Subyek dalam penelitian ini adalah masyarakat Kabupaten Pidie Jaya. Metode yang digunakan dalam studi ini adalah deskriptif kualitatif dengan data yang berasal dari data wawancara dan dokumentasi. Hasil penelitian dari proses triangulasi menunjukkan bahwa partisipasi dan pemberdayaan masyarakat Kabupaten Pidie Jaya dalam Upaya Pengurangan Risiko Bencana Berbasis Komunitas masih belum berjalan dengan optimal, namun telah meningkatkan pemahaman terhadap ilmu kebencanaan di kawasan tersebut meliputi pengetahuan,
\end{abstract}


budaya, antisipasi, dan mitigasi. Prinsip Building Back Better diterapkan oleh Pemerintah Pidie Jaya yaitu dengan rekonstruksi kehidupan kelompok komunitas melalui minimalisir kerentanan dan meningkatkan kemampuan guna menghindari faktor risiko bencana di masa depan. Pendekatan melalui tokoh agama dan dayah turut ikut serta dalam memberikan sosialisasi dan edukasi. Hasil dari PRBBK Pidie Jaya adalah pembentukan dua Desa/Gampong Tangguh Bencana yang berada di kawasan pesisir, yaitu Desa Lancang Kec. Bandar Baru dan Desa Meuraksa Kec. Meureudu.

Kata Kunci: Risiko Bencana, Pengurangan Risiko Bencana Berbasis Komunitas (PRBBK), kapasitas masyarakat, Pidie Jaya.

\section{PENDAHULUAN}

Bencana merupakan gangguan serius pada peranan kelompok komunitas atau masyarakat yang menyertakan kerugian yang berdampak kepada manusia, material, dan perekonomian. (UNISDR, 2009). Hal ini berimbas pula pada kawasan yang lebih luas melebihi kapasitas kelompok atau masyarakat yang terdampak untuk mengatasinya dengan menggunakan kekuatanr dayanya sendiri. Penggambaran bencana diidentifikasi dari unifikasi paparan ancaman, situasi kerentanan, dan kemampuan.

Kabupaten Pidie Jaya merupakan kawasan yang rawan terhadap risiko bencana seperti gempa bumi, tsunami, dan banjir (Jaya, 2020). Keadaan ini karena dipengaruhi oleh kondisi geografis yang mana cakupan dari seluruh kawasan Kabupaten Pidie Jaya adalah wilayah pesisir dan pegunungan. Adanya Great Sumatran Fault yang membentang dari Lampung sampai laut Adaman menyumbangkan keadaan aktivitas tektonik yang sangat tinggi pula (Zainal et al., 2020). Kilas balik pada tanggal 7 Desember tahun 2016, gempa bumi yang berpusat pada Kabupaten Pidie Jaya mengakibatkan 104 orang meninggal dunia. Serta tragedi tak terlupakan yaitu bencana tsunami pada tahun 2004 menyebabkan banyak sekali kerugian mulai dari korban jiwa, infrastruktur, bahkan trauma yang dirasakan para pengungsi.

Pengurangan Risiko Bencana (PRB) menjadi strategi yang dapat diterapkan sebagai upaya untuk meramalkan risiko bencana di masa depan, menekan kerentanan saat ini, dan meningkatkan ketahanan pada Kabupaten Pidie Jaya (Forino et al., 2015). Konsep ini secara sistematis menelaah dan mengatur faktor kausa bencana termasuk melalui minimalisir paparan musibah, berkurangnya susebtibilitas jiwa dan harta benda, penggarapan tanah dan lingkungan yang bijaksana, serta eskalasi kesiapsiagaan untuk kondisi yang terburuk (UNISDR, 2009). Laporan yang dikeluarkan oleh BNPB (2016) menekankan bahwa dalam penyelenggaraan penanggulangan bencana parameter kapasitas daerah penting dalam penentuan keberhasilan PRB. Kerangka Aksi Hyogo yang telah disepakati oleh 160 negara menjadi salah satu acuan dasar dari PRB pada pembangunan kapasitas.

Penelitian ini berfokus kepada penilaian kapasitas kelembagaan sosial pada tingkat lokal yaitu kesiapsiagaan bencana berbasis komunitas yang meliputi partisipasi dan pemberdayaan sumber daya lokal. Potensi ini akan menunjukkan bagaimana kerentanan dalam konteks bencana alam di masyarakat (Allen, 2006). Pendekatan Pengurangan Risiko Bencana Berbasis Komunitas (PRBBK) menekankan kemandirian masyarakat, meningkatkan kesadaran akan kerentanan, dan mengidentifikasi akar penyebab bencana, serta bagaimana mengembangkan keterampilan praktis masyarakat untuk memecahkan masalah. Dalam hal ini, PRBBK bertujuan dalam meningkatkan kemampuan masyarakat untuk merespon dengan cepat dan mudah serta beradaptasi terhadap keadaan lingkungan yang rawan terhadap bencana dengan mengacu pada situasi dan kondisi spesifik lokal.

Dengan dilakukan penelitian ini maka akan menghasilkan analisis yang menganalisa dan menciptakan kapasitas kelompok komunitas serta elemen yang terkait sebagai upaya meminimalisir risiko bahaya melalui pencegahan, mitigasi, kesiapsiagaan, dan penanganan darurat (Oxfam, 2012). Untuk menciptakan daerah dan masyarakat yang tangguh dalam menghadapi bencana maka diperlukan partisipasi dan pemberdayaan sumber daya lokal di Kabupaten Pidie Jaya. Upaya 
PRBBK ini diharapkan dapat berhilir pada terwujudnya kepentingan nasional Indonesia yaitu menciptakan keselamatan segenap bangsa Indonesia.

\section{METODE PENELITIAN}

Metode penelitian yang digunakan pada penelitian ini adalah kualitatif deskriptif. (Creswell, 2016). Penelitian ini menggunakan data yang bersumber dari data primer (wawancara) dan sekunder (dokumentasi). Subyek yang diteliti merupakan masyarakat Kabupaten Pidie jaya Provinsi Aceh. Informan yang dipilih dalam studi ini menggunakan teknik purposive sampling yaitu Kepala Pelaksana Badan Penanggulanan Bencana Daerah (BPBD), Kepala Bidang Tata Lingkungan dan Penataaan Dinas Lingkungan Hidup, Sekretaris Forum Pengurangan Risiko Bencana Kabupaten Pidie Jaya, Plt. Kepala Dinas Kesehatan dan Keluarga Berencana, Kepala Dinas Sosial, Tenaga Kerja dan Transmigrasi, Kepala Bappeda, serta Akademisi dari Universitas Syiah Kuala Provinsi Aceh.

Teknik wawancara dilakukan secara bebas dan di rancang dengan konsep diskusi atau Focus Group Discussion (FGD) dengan nara sumber sebagai informan. Teknik triangulasi digunakan dalam melakukan validasi data dengan melakukan investigasi data yang sama dari bermacam-macam sumber yang didapatkan yang kemudian dilakukan analisis sesuai dengan kerangka penelitian yang berproses bersama dengan dimensi lain dari uraian penelitian kualitatif, yaitu akumulasi data (Neuman, 2017) tentang partisipasi dan pemberdayaan sumber daya lokal dala pengurangan risiko bencana yang dilakukan dari 22 Maret-26 Maret 2021 di Kabupaten Pidie Aceh.

\section{HASIL DAN PEMBAHASAN}

Usaha pemberdayaan masyarakat untuk mengendalikan risiko bencana dengan derajat peran serta pihak atau komunitas masyarakat dalam merencanakan dan memanfaatkan kapasitas kekuatan lokal pada kegiatan pelaksanaan oleh masyarakat sendiri adalah pengertian dari Penanggulangan Risiko Bencana Berbasis Komunitas (PBBK) atau sinonim dari Pengurangan Risiko Bencana Berbasis
Komunitas (PRBBK) atau yang juga disebut Community Based Disaster Risk Management (CBDRM) (Abarquez \& Murshed, 2004). Dalam konsep PBBK/PRBBK, terdapat prinsip-prinsip dasar yaitu partisipatif, pemberdayaan, demokratis, dan pemanfaatan sumber daya lokal, dengan di dampingi oleh pemangku kebijakan di Pemerintahan atau lembaga Non Pemerintah yang hanya bersifat membantu dan mendukung. (Maarif Syamsul, 2020). Oleh karenanya masyarakat sendiri yang memegang peranan penting dalam upaya pengurangan risiko bencana.

Metode dalam PRBBK terdiri dari (Nugroho, Kharisma dan Yon, 2011):

1) Otorisasi paling tinggi ditangan kelembagaan berbasis komunitas yang diberi mandat;

2) Analisis risiko ancaman, pengelolaan risiko, kesiapsiagaan (intinya mengantisipasi), strategi mitigasi (menutup hal-hal yang belum terjangkau dengan kesiapsiagaan, diluar antisipasi) dan rehabilitasi dilaksanakan dengan peran serta penuh oleh masyarakat;

3) Intervensi eksternal bersifat multi sektor, lintas sektor, dengan tidak melahirkan "ketergantungan" baru;

4) Didukung oleh budaya lokal, keahlian lokal dan kearifan lokal yang digabungkan dengan pengetahuan modern (teknologi).

Penanggulangan Bencana Berbasis Komunitas (PBBK)/PRBBK sejatinya melibatkan partisipasi penuh dari masyarakat. Twigg (2006), menjelaskan bahwa makna komunitas dalam PRBBK diperluas menjadi 3 (tiga) pemahaman, yaitu: (1) eksistensi peran serta menyeluruh yang melibatkan pula peran serta pihak yang berisiko, seperti kanak-kanak, kelompok wreda, orang-orang yang membutuhkan kebutuhan khusus, ras rendah, dan sebagainya; (2) persamaanya adalah secara hirarki dari bawah keatas (bottom-up) bukan dari atas kebawah (top-down), peran serta menyeluruh, akses dan otorisasi, strategi secara komprehensif rasa memiliki terhadap program penanganan bencana yang telah, tengah, dan akan dibangun. Strategi top-down pada permulaan aktivitas memberikan peluang untuk dilakukan, namun sejalan dengan waktu, kelompok komunitas dipersiapkan untuk dapat independ sehingga mekanisme bottom-up dapat lebih menonjol dan (3) menggunakan metode 
"dari, oleh, dan untuk" komunitas dalam keutuhan cara, di mana masyarakat yang mengelola teknik dan bukan dikelola teknis (Lassa et al., 2014).

Dalam konsep Penanggulangan Bencana Berbasis Komunitas atau PBBK (PRBK), masyarakat merupakan kunci utama yang secara aktif, partisipatif dan terorganisir dengan baik dapat melakukan serangkaian upaya atau kegiatan untuk meminalisir kerentanan bencana. Dengan partisipasi aktif masyarakat ini diharapkan mampu mengidentifikasi dan mengerti potensi wilayah mereka, memetakan berbagai potensi bahaya di wilayah mereka, juga mengetahui potensi sumber daya lokal yang ada (Djalante \& Garschagen, 2017).

Salah satu penyebab minimnya kapasitas masyarakat dalam pengurangan risiko bencana adalah masih banyaknya masyarakat yang bermukim di daerah rawan bencana.

Masyarakat yang ada tidak mungkin dipindahkan dari tempat bermukim saat ini karena hal tersebut terkait dengan perekonomian masyarakat. Disinilah pentingnya melihat aspek kearifan lokal, agar upaya pengurangan risiko bencana dapat tetap dilakukan tanpa mengganggu aspek kehidupan masyarakat lainnya.

Untuk mengantisipasi hal tersebut adalah dilakukan penguatan pada regulasi tata ruang dan wilayah, dimana didalamnya terdapat pengaturan mengenai wilayah-wilayah tertentu yang harus diperkuat melalui penguatan mitigasi non struktural.

Masyarakat di Kabupaten Pidie Jaya Provinsi Aceh mempunyai bentuk partisipasi dalam pengurangan risiko bencana antara lain dengan upaya mitigasi melalui usaha fisik dan non fisik. Upaya mitigasi melalui usaha fisik seperti penataan rumah berbasis PRB pada proses pemulihan pasca bencana. Program ini digagas oleh Pemerintah Kab. Pidie Jaya dengan menggunakan prinsip "Building Back Better", yaitu dengan rekonstruksi kehidupan kelompok komunitas melalui pengurangan kerentanan dan meningkatkan kemampuan untuk menghindari faktor risiko bencana di masa depan.

Prinsip ini sesuai dengan studi yang dilakukan oleh Sagala et al (2013) yang menganalisa interaksi aktor dan rekontruksi yang menyatakan bahwa penanganan dan pengelolaan rekonstruksi hunian pasca bencana di Kecamatan
Pangalengan, bandung terjadi melalui keikutsertaan 41 (empat puluh satu) pelaku yang terdiri dari elemen pemerintahan pusat, pemerintah daerah, pemerintah setempat, organisasi penanggulangan bencana, unsur (teknis) yang terkait, masyarakat, organisasi donatur dan badan usaha, serta pelaku dari unsur eksternal.

Berdasarkan data yang didapat dari Renaksi Rehabilitasi dan Renkontruksi Pasca Bencana Gempa Tahun 2017-2019, hasil asesmen menunjukkan sebanyak 3.205 rumah rusak berat dan 3.269 rumah rusak sedang, sehingga total terdapat 6.474 unit rumah yang akan di bangun kembali dengan menggunakan prinsip building back better. Plt Kalaksa BPBD menyatakan selama ini masyarakat membangun rumah dengan dana swadaya tanpa memperhatikan aturan, maka melalui konsep building back better ini masyarakat Kab. Pidie juga akan diikutsertakan dalam pembangunan rumah hunian sebagai upaya pengurangan risiko bencana. Sedangkan upaya mitigasi secara individu maupun komunitas melalui usaha-usaha non fisik diantaranya melalui Forum Pengurangan Risiko Bencana (FPRB) yang terdiri dari tokoh masyarakat, pejabat desa, LSM, media massa dan lembaga/instansi terkait yang bersinergi dalam penanggulangan bencana. FPRB berperan diantaranya dalam identifikasi kawasan rawan bencana juga dalam penyampaian informasi kebencanaan agar terbentuk sistem kewaspadaan dini di masyarakat.

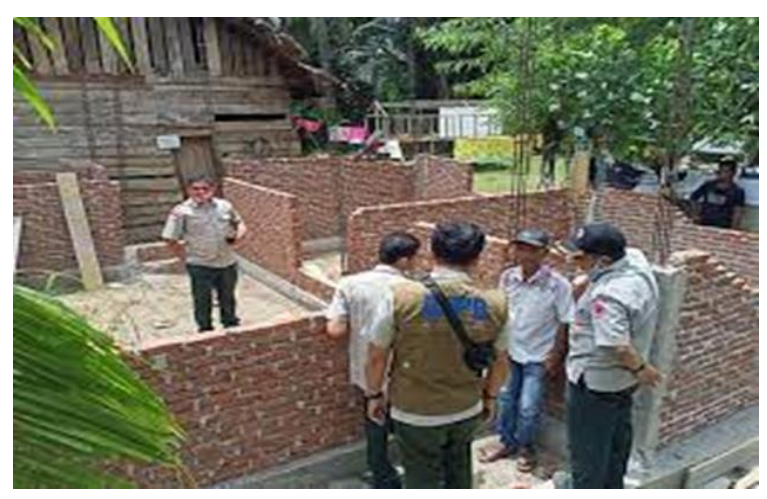

Gambar 1. Pembangunan Rumah Ramah Gempa Rehab Rekon Pasca Bencana Gempa Bumi

Sejalan dengan pernyataan tersebut, hambatan yang terjadi dalam pelaksanaan 
perancangan tata ruang berdasarkan peran serta masyarakat dalam mitigasi bencana alam di Kelurahan Laksana Kota Banda Aceh, salah satunya adalah keikutsertaan masyarakat dalam perencanaan secara teknis yang minim maka dalam pemberdayaan terletak pada interpretasi perencanaan. Selanjutnya dalam implementasi perencanaan, komunitas dapat ikut serta dalam proses perawatan dan pengontrolan perencanaan. Ini menandakan bahwa pemberdayaan itu harus diinisiasi dengan desiminasi informasi yang harus di follow up dengan metode pembinaan terhadap kelompok komunitas tersebut. Dalam mendayagunakan masyarakat harus ada proteksi kepada komunitas lemah dalam artian masyarakat memiliki kedudukan yang sama untuk mendapatkan dukungan dan kekuatan sehingga tidak berlaku lagi stigma yang kuat akan terus kuat dan yang lemah akan semakin dilemahkan (Rozi, 2008).

Dalam beberapa hal partisipasi masyarakat masih terbatas pada peningkatan kesadaran dan kewaspadaan, serta menunggu upaya pemerintah untuk penanggulangan bencana, yang salah satunya melalui FPRB yang menjadi kepanjangan tangan dari Pemerintah (BPBD) dalam memberikan informasi, edukasi dan sosialisasi kepada masyarakat. Seperti pada penanggulangan Covid-19, dimana partisipasi masyarakat Kab. Pidie Jaya masih minim.

Ini dapat dilihat masih banyaknya kelompok komunitas yang terjaring dalam operasi yustisi dalam hal penerapan protokol kesehatan seperti memakai masker. Sebagian besar masyarakat sudah paham bahwa keluar rumah harus memakai masker, namun masker tersebut tidak digunakan melainkan disimpan dikantong/saku pakaian. Kebijakan-kebijakan khususnya dalam penanggulangan bencana non alam berupa pandemi Covid-19 yang telah ditetapkan oleh Presiden RI melalui BNPB, Kemendagri dan lintas Kementerian terkait belum dapat diterima sepenuhnya oleh masyarakat, termasuk kebijakan vaksinasi.

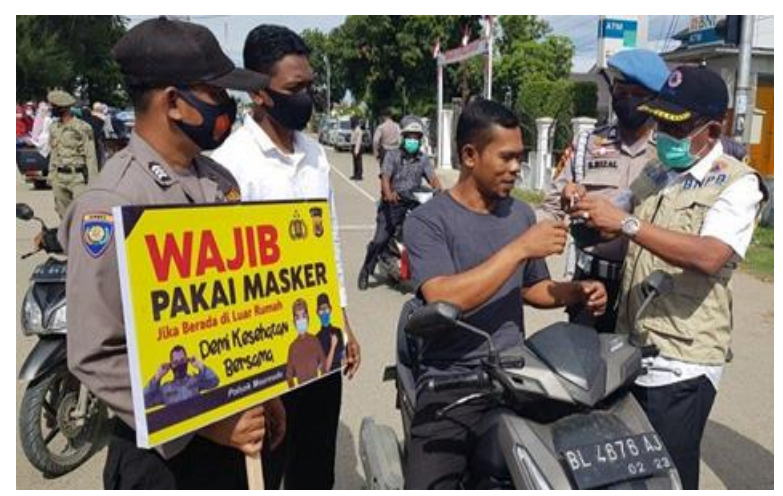

Gambar 2. Kegiatan Gugus Tugas Bekerja Sama dengan Kepolisian Membagian Masker dalam Penanganan Covid-19

Masih minimnya parsitipasi penyintas bencana selaras dengan penelitian yang dilakukan oleh Ayu \& Surtiari (2019) yang menyimpulkan bahwa walaupun telah ada peran serta yang terbuka dari penyintas bencana, namun belum menyentuh secara utuh kepada penyintas bencana. Para donatur atau kontraktor masih masih sebatas berusaha memberikan bantuan kepada penyintas sebatas bantuan fisik.

Menurut Azmeri et al. (2017) dalam penelitiannya menyimpulkan bahwa ada empat dimensi yang menjadi hambatan dan penunjang proses rehabilitasi dan rekonstruksi pemukiman pascabencana di Aceh. Yaitu (1) proses pelimpahan pemukiman, (2) peran serta masyarakat dalam rancangan dan pengontrolan permukiman, (3) logistik material bangunan dan sumber daya manuasia terampil, dan (4) peran serta dan kebijakan pemerintah.

Kerjasama juga merupakan faktor penting yang sering dilalaikan. Strategi yang dilakukan oleh Pemerintah Kab. Pidie Jaya adalah dengan melakukan pendekatan melalui tokoh-tokoh agama dan dayah-dayah (lembaga pendidikan trandisional islam) dari pondok pesantren untuk memberikan sosialisasi dan edukasi, mengingat Kab. Pidie Jaya terkenal sebagai Kabupaten santri. 


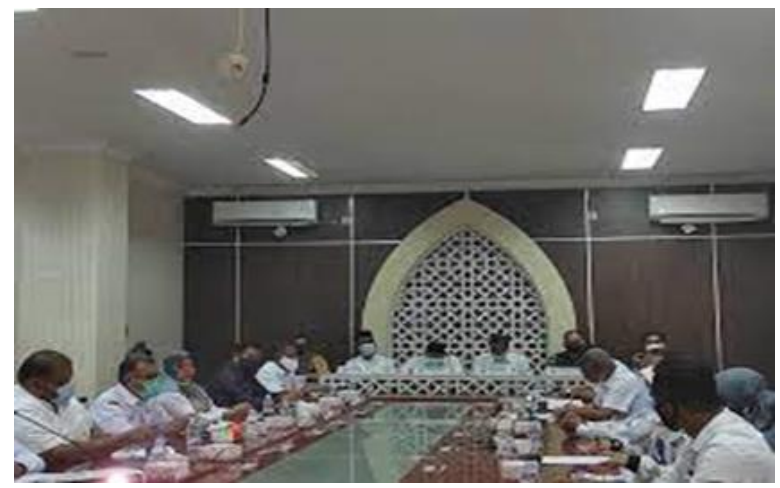

Gambar 3. Peran Serta Tokoh Agama dalam Kegiatan Kebencanaan

Dalam hal budaya lapor kasus Covid-19, partisipasi asyarakat sudah cukup baik, bahkan Pak Geuchik (Kepala Desa) sendiri yang datang untuk melapor kepada dinas jika ada warganya yang meninggal terkait dugaan kasus Covid-19. Pendekatan PRBBK juga merekomendasikan kegiatan pemberdayaan masyarakat untuk mengatasi akar penyebab kerentanan dengan mendorong transformasi atau perubahan pada struktur sosial, ekonomi dan politik yang menimbulkan ketidakadilan dan keterbelakangan (United Nations Centre for Regional Development, 2004). Dalam pemberdayaan masyarakat, intervensi dari pemerintah maupun bantuan eksternal tidak menimbulkan ketergantungan baru dan menstimulasi masyarakat untuk dapat bangkit kembali secara lebih baik.

Data yang didapat melalui forum Focus Group Discussion (FGD) Dalam upaya PRBBK berbasis pemberdayaan masyarakat, Pemerintah Kab. Pidie Jaya telah menganggarkan Rp. 500.000.000,- (Lima Ratus Juta Rupiah) untuk pelatihan penanggulangan bencana yang akan dilaksanakan di Desa/Gampong yang ada di Pidie Jaya. Namun, keterbatasan anggaran tersebut menyebabkan tidak semua Desa di Kab. Pidie Jaya dapat memperoleh pelatihan ini.

Sebagai target awal pada tahun ini, pelatihan akan dilaksanakan di 50 Desa dengan perwakilan sebanyak 5 tokoh masyarakat dari masingmasing desa akan dilatih dan merupakan tokohtokoh kunci dalam rangka penanggulangan bencana. Pelatihan ini meliputi pelatihan kebencanaan, pamahaman masyarakat, program ketahanan pangan dan konservasi masalahmasalah lingkungan.
Penelitian ini didukung oleh studi yang dilakukan oleh (Widianto, 2019) yang menyimpulkan bahwa konseling atau diseminasi, pendidikan dan pelatihan simulasi bencana dan mitigasnya merupakan salag satu metode yang dapat dilakukan dalam edukasi kebencanaan ditengah kelompok komunitas, sehingga harapannya setiap anggota komunitas dan keluarga sebagai bagian terkecil menjadi pelopor dalam mewujudkan masyarakat yang sadar dan siaga bencana.

Penelitian yang lain menyatakan bahwa dorongan untuk melaksanakan pelatihan merupakan salah satu proses untuk membangun munculnya mindset positif. Training bencana lebih efisien dan dapat diterima, jika diintegrasikan dengan modul keselamatan dan kesehatan kerja di lingkungan universitas sehingga lebih gampang diterima oleh peserta pelatihan. (Utami \& Nanda, 2019)

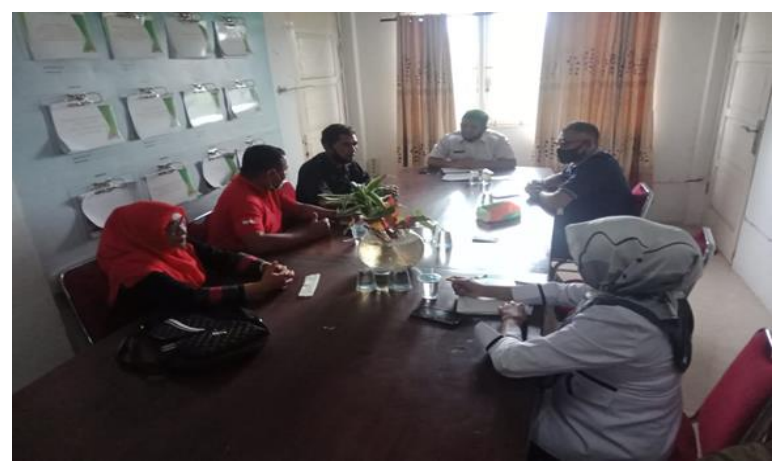

Gambar 4. Koordinasi Bersama stakeholder Forum Pengurangan Resiko Bencana Kabupaten Pidie Jaya

Pemerintah Kab. Pidie Jaya juga telah membentuk 2 (dua) Desa/Gampong Tangguh Bencana yang merupakan Desa yang berada di kawasan pesisir, yaitu Desa Lancang Kec. Bandar Baru dan Desa Meuraksa Kec. Meureudu. Di Desa Lancang, pemerintah membuat jalur evakuasi, titik kumpul dan diberikan pelatihan pada masyarakat bagaimana upaya yang dapat dilakukan dalam mendukung perekonomian karena di daerah tersebut terdapat usaha tambak ikan, tambak udang dan petani garam.

Dampak akibat bencana banjir tersebut merupakan kerugian materi yang sangat besar bagi para petani. Selain berisiko menyebabkan para petani menjadi fakir dalam perekonomian, 
ini juga akan berdampak memangkas atau menghilangkan cadangan bahan makanan di daerah yang terdampak akibat bencana banjir. Dengan layar belakang tersebut, maka diperlukan koordinasi dan kerja sama publik antar para stakeholder baik di pemerintahan daerah maupun puasat hingga komunitas petani dapat bersinergi melaksanakan program program mitigasi bencana banjir yang dapat menghambat TPB tersebut. Program lain adalah bersama dengan perangkat desa dan kelompok tani terlibat dalam kegiatan diseminasi tentang perlunya konservasi lahan di lahan pertanian.(Taslim \& Akbar, 2019). Sedangkan untuk Desa Meuraksa baru dibentuk pada masa pandemi Covid-19 ini guna membentuk desa tangguh terhadap bencana dalam rangka ketahanan pangan dengan adanya industri rumah tangga berbasis kuliner dan peternakan (penggemukan sapi).

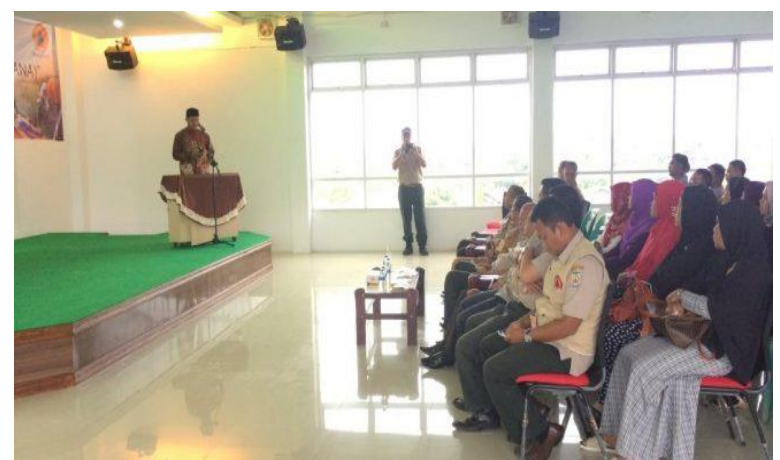

Gambar 5. Seminar Desa Tangguh Bencana

Melihat pengalaman pada aktivitas eskalasi daya lenting di Desa Lam Teungoh, Kecamatan Peukan Bada, Aceh Besar dalam hal pembentukan Desa Tangguh Bencana yang dilaksanakan pada termin awal akan memunculkan beberapa output, yakni meningkatnya pengetahuan komunitas; pemahaman komunitas yang bertambah; terorganisasinya Dokumen PRB, denah Risiko Bencana, dan denah Evakuasi Bencana Desa Lam Teungoh; serta lahirnya Forum PRB Desa Lam Teungoh. Kegiatan ini juga mengenalkan kebutuhan training komunitas ibu-ibu dan remaja dalam usaha menambah ketahanan ekonomi kelompok komunitas Desa Lam Teungoh. (Oktari, 2019)

Disinilah terbentuk upaya partisipatif dan pemberdayaan dari masyarakat seperti pelibatan dalam kegiatan penanaman pohon bakau, dan membuat batu pemecah ombak di pesisir pantai yang mengenai hal ini juga sudah diperkuat dalam regulasi di kawasan pesisir yang ada, upaya penguatan dinding sungai dan penguatan abrasi pantai di beberapa titik yang termasuk dalam kategori sangat mengancam.

Namun upaya ini mengalami kendala karena keterbatasan anggaran dari APBD. Usaha mitigasi penguatan dinding sungai dan abrasi pantai ini merupakan kewenangan dari Kementerian PUPR, hal inilah yang menjadi kendala bagi pemerintah Kab. Pidie Jaya sehingga tidak dapat segera melakukan pembangunan. Oleh karenanya dibutuhkan solusi bersama dengan sinergitas pentahelix.

\section{KESIMPULAN}

Partisipasi masyarakat merupakan kekuatan yang dapat diandalkan, terutama pada saat kesulitan seperti becana terjadi. Pengetahuan dan kemampuannya harus dibina, dikembangkan, dan ditingkatkan dengan tetap menjalin kebersamaan dengan unsur kelembagaan penanggulangan bencana terkait.

Partisipasi masyarakat merupakan salah satu bentuk mitigasi bencana non struktural yang harus didukung oleh program mitigasi struktural dalam bentuk bangunan fisik sebagai sistem pertahanan pantai. Kegiatan partisipasi masyarakat pada setiap langkah untuk menghadapi bencana di Pidie Jaya Provinsi Aceh merupakan upaya untuk mengurangi risiko bencana yang dilaksanakan atas dasar kesadaran, kebersamaan dan keterpaduan antara masyarakat, pemerintah dan pihak lain yang berkaitan dengan aspek kebencanaan

Gerakan pengabdian masyarakat ini telah memberikan efek meningkatnya pemahaman masyarakat di Kabupaten Pidie Jaya, antara lain pengetahuan yang bertambah dan timbulnya budaya kesadaran mengenai pentingnya Penanggulangan Risiko Bencana Berbasis Komunitas atau PBBK/ Pengurangan Risiko Bencana Berbasis Komunitas (PRBBK), serta berkontribusi dalam penafsiran dasar untuk tindakan antisipasi dan mitigasi bencana yang mungkin terjadi. Training dan sosialisasi juga diharapkan akan menambah kesiapsiagaan dan resiliensi masyarakat menghadapi bencana. 
Pemberdayaan masyarakat dalam
pengurangan risiko bencana banjir di Kabupaten Pidi Jaya Provinsi Aceh telah dilaksanakan oleh BPBD Kabupaten Pidie Jaya yang bekerja sama secara lintas sektoral seperti Dinas Lingkungan Hidup, Forum Pengurangan Risiko Bencana Kabupaten Pidie Jaya, Dinas Kesehatan dan Keluarga Berencana, Dinas Sosial, Tenaga Kerja dan Transmigrasi, Bappeda, serta Akademisi dari Universitas Syahkuala Provinsi Aceh. Namun, fenomena yang didapatkan peneliti saat penelitian adalah kurang optimalnya partisipasi dan pemberdayaan kelompok masyarakat di Pidie jaya. Pertama, adanya ketergantungan masyarakat terhadap instansi pemerintahan merupakan salah satu penyebab dari masalah ini. Kedua, pelatihan tentang kebencanaan masih belum optimal dan efisien oleh karena masalah sumber dana. Untuk itu disarankan kepada instansi pemerintah dalam melaksanakan penberdayaan terhadap masyarakat terlebih dalam hal kebencanaan agar hal itu dilaksanakan secara komprehensif dan lebih serius.

\section{DAFTAR PUSTAKA}

Abarquez, I., \& Murshed, Z. (2004). Community Based Disaster Risk Management: Field Practitioners' Handbook. http://info.worldbank.org/etools/docs/librar y/230352/Session-3/Reading 3 - ADPC Handbook.pdf

Allen, K. M. (2006). Community-based disaster preparedness and climate adaptation: local capacity-building in the Philippines. Disasters, $\quad 30(1), \quad 81-101$. https://doi.org/https://doi.org/10.1111/j.146 7-9523.2006.00308.x

Ayu, G., \& Surtiari, K. (2019). Pentingnya Penanganan Pascabencana Yang Berfokus Pada Penduduk Untuk Mewujudkan Build Back Better: Pembelajaran Dari Bencana Palu , Sigi, Dan Donggala ( the Importance of People Center Approach in the Post Disaster Management To Support Build Back Bette. 14(2), 165-184. https://doi.org/https://doi.org/10.14203/jki.v $14 \mathrm{i} 2.443$

Azmeri, A., Mutiawati, C., Al-Huda, N., \&
Mufiaty, H. (2017). Disaster Recovery Indicators of Housing Reconstruction: The Story of Post Tsunami Aceh, Indonesia. International Journal of Disaster Management, $\quad 1(1), \quad 35-45$. http://jurnal.unsyiah.ac.id/IJDM/article/vie w/8036

BNPB. (2016). Risiko Bencana Indonesia (R. Jati \& M. R. Amri (eds.)).

Creswell, J. W. (2016). Research Design. Pustaka Pelajar. https://doi.org/https://doi.org/10.31113/jia.v $5 \mathrm{i} 3.452$

Djalante, R., \& Garschagen, M. (2017). A review of disaster trend and disaster risk governance in Indonesia: 1900-2015. Disaster Risk Reduction in Indonesia, 2156.

https://doi.org/https://doi.org/10.1007/9783-319-54466-3_2

Forino, G., von Meding, J., \& Brewer, G. J. (2015). A conceptual governance framework for climate change adaptation and disaster risk reduction integration. International Journal of Disaster Risk Science, 6(4), 372-384. https://doi.org/10.1007/s13753-015-0076-z

Jaya, P. K. P. (2020). Qanun Kabupaten Pidie Jaya Nomor 3 Tahun 2020 Tentang Rencana Pembangunan Jangka Menengah (RPJM) Kabupaten Pidie Jaya Tahun 20192024.

Lassa, J., Paripurno, E. teguh, Jannah, ninil M., Pujiono, P., Magatari, A., Pristianto, J., Sudira, C., \& Parlan, H. (2014). Panduan Pengelolaan Risiko Bencana Berbasis Komunitas (PRBBK) (Issue September).

Maarif Syamsul. (2020). Bahan Ajar Pengurangan Risiko Bencana Berbasis Komunitas. Universitas Pertahanan.

Neuman, W. (2017). Social Research Methods: Qualitative and Quantitative Approaches. In Teaching Sociology (Vol. 30). https://doi.org/10.2307/3211488

Nugroho, Kharisma dan Yon, K. M. (2011). Pengurangan Resiko Bencana Berbasis Komunitas di Indonesia.Laporan Penelitian Gerakan, Pelembagaan, dan Keberlanjutan dari Perspektif Gerakan sosial di Indonesia.

Oktari, R. S. (2019). Peningkatan Kapasitas Desa 
Tangguh Bencana. Jurnal Pengabdian Kepada Masyarakat (Indonesian Journal of Community Engagement), 4(2), 189. https://doi.org/10.22146/jpkm.29960

Oxfam. (2012). Analisis kerentanan dan Kapasitas Partisipatif Oxfam: Sebuah Pedoman Praktisi. Oxfam Indonesia.

Rozi, A. (2008). Perencanaan tata Ruang Berbasis Partisipasi Masyarakat Dalam Mitigas Bencana Alam di kelurahan Laksana Kota Banda Aceh. 5(3), 276-300. https://doi.org/DOI: hhttps://doi.org/10.31113/jia.v5i3.452

Sagala, S. A. H., Situngkir, F., \& Wimbardana, R. (2013). Interaksi Aktor dalam Rekonstruksi Rumah Pasca Bencana Gempa Bumi. Mimbar: Jurnal Sosial Dan Pembangunan, 29(2), 217-226. https://doi.org/https://doi.org/10.29313/mi mbar.v29i2.397

Taslim, I., \& Akbar, M. F. (2019). Koordinasi Publik untuk Pengurangan Risiko Bencana (PRB) Banjir pada Pelaksanaan Pembangunan Berkelanjutan Gorontalo. Jurnal Wilayah Dan Lingkungan, 7(2), 6378. https://doi.org/10.14710/jwl.7.2.63-78

Twigg, J. (2006). Disaster Early Warning Systems: People, Politics and Economics. https://doi.org/10.13140/RG.2.2.15403.264 01

UNISDR. (2009). Disaster. International Strategy for Disaster Reduction. https://doi.org/10.1021/cen-v064n005.p003
United Nations Centre for Regional Development. (2004). Sustainable Community Based Disaster Management (CBDM) Practices in Aisa: A user's guide (O. K. Rajib, Shaw (ed.)). http://www.hyogo.uncrd.or.jp/publication/p df/Guide/CBDMUsersGuide.pdf

Utami, T. N., \& Nanda, M. (2019). Pengaruh Pelatihan Bencana Dan Keselamatan Kerja Terhadap Respons Persepsi Mahasiswa Prodi Ilmu Kesehatan Masyarakat. JUMANTIK (Jurnal Ilmiah Penelitian Kesehatan), 4(1), 83. https://doi.org/10.30829/jumantik.v4i1.412 7

Widianto, E. (2019). Implementasi pelaksanaan pelatihan kesiapsiagaan dalam menghadapi bencana Bagi generasi muda. Jurnal Graha Pengabdian, 1(2), 128-138.

Zainal, M., Marwan, M., Yanis, M., \& Muksin, M. (2020). Pengurangan Resiko Bencana Berbasis Komunitas Melalui Pembentukan Desa Tangguh Bencana di Kabupaten Pidie Jaya Nanggroe Aceh Darussalam. Engagement: Jurnal Pengabdian Kepada Masyarakat, 4(1), 237-251. https://doi.org/10.29062/engagement.v4i1.1 06 